Artículo científico

(Original paper)

\title{
FACTORES ABIÓTICOS Y BIÓTICOS DETERMINANTES PARA LA PRESENCIA DE BATRACHOCHYTRIUM DENDROBATIDIS EN ANFIBIOS MEXICANOS
}

\author{
DETERMINANT ABIOTIC AND BIOTIC FACTORS FOR THE PRESENCE OF \\ BATRACHOCHYTRIUM DENDROBATIDIS IN MEXICAN AMPHIBIANS
}

\author{
Luis Manuel GARCÍA FERIA ${ }^{1,3 *}$, Dulce María BROUSSET ${ }^{1}$, Roberto ARnUlFo CERVANTES \\ OLIVARES ${ }^{2}$

\begin{abstract}
${ }^{1}$ Departamento de Etología, Fauna Silvestre y Animales de Laboratorio. Facultad de Medicina Veterinaria y Zootecnia, Universidad Nacional Autónoma de México, Ciudad de México, 04510, México. <luis.garcia@inecol.mx>; <brousset@unam.mx>

${ }^{2}$ Laboratorio de Micología. Departamento de Inmunología y Microbiología. Facultad de Medicina Veterinaria y Zootecnia, Universidad Nacional Autónoma de México, Ciudad de México, 04510, México. <raco@unam.mx>

${ }^{3}$ Red de Biología y Conservación de Vertebrados. Instituto de Ecología, A. C. Carretera antigua a Coatepec No. 351 . E1 Haya. 91073. Xalapa, Veracruz, México.<luis.garcia@inecol.mx>

*Autor de correspondencia: <luis.garcia@inecol.mx>
\end{abstract}

Recibido: 09/08/2018; aceptado: 19/02/2019; publicado en línea: 10/07/2019

Editor responsable: Alberto González Romero

García-Feria, L. M., Brousset, D. M., Cervantes-Olivares, R. A. (2019) Factores abióticos y bióticos determinantes para la presencia de Batrachochytrium dendrobatidis en anfibios mexicanos. Acta Zoológica Mexicana (nueva serie), 35, 1-18. https://doi.org/10.21829/azm.2019.3502066

RESUMEN. Evaluamos la presencia de Batrachochytrium dendrobatidis (Bd) en 13 especies de anfibios mexicanos asociada a factores abióticos y bióticos como un modelo de distribución de especies mediante árboles de clasificación y regresión (CART). El hongo quítrido fue diagnosticado a partir de hisopados cutáneos de anfibios adultos, y frotis orales de renacuajos por medio de PCR anidada para un fragmento de rRNA de $300 \mathrm{pb}$. Los especímenes fueron muestreados en siete tipos de vegetación durante las temporadas seca y lluviosa. El hongo quítrido se detectó por primera vez en Charadrayla taeniopus y Leptodactylus fragilis, especies en las que no se había registrado previamente; también se confirmó su presencia en anfibios de la selva alta perennifolia del sureste de México. De acuerdo con los CART, las dos variables más importantes para la ocurrencia de $\mathrm{Bd}$ son la especie del hospedero y la precipitación, pero su combinación con otras variables como el estado de desarrollo, la temperatura ambiental, la temporada climática, el tipo de vegetación y altos índices de vida acuática influyen en la presencia del hongo quítrido. Además, se obtuvo que los renacuajos tienen 1.52 veces más prevalencia de $\mathrm{Bd}$ que los adultos, y los renacuajos de dos especies de anfibios estudiadas son potencialmente reservorios. Aunque ningún anfibio mostró signos clínicos de quitridiomicosis, nuestros hallazgos indican que la presencia y la persistencia de Bd pueden estar relacionadas con la susceptibilidad o resistencia de las especies y la interacción de diversos factores abióticos y bióticos.

Palabras clave: Estacionalidad; PCR anidada; renacuajos; índice de vida acuática; modelo de distribución de especies; CART 
García-Feria et al.: Determinantes para la presencia de Batrachochytrium

dendrobatidis en anfibios

García-Feria, L. M., Brousset, D. M., Cervantes-Olivares, R. A. (2019) Determinant abiotic and biotic factors to the presence of Batrachochytrium dendrobatidis in Mexican amphibians. Acta Zoológica Mexicana (nueva serie), 35, 1-18. https://doi.org/10.21829/azm.2019.3502066

\begin{abstract}
We evaluated the presence of Batrachochytrium dendrobatidis (Bd) in 13 Mexican amphibians associated to abiotic and biotic factors as a species distribution model by a classification and regression tree (CART). Chytrid fungus was diagnosed from cutaneous swabs in adults' amphibians and oral swabs of tadpoles by nested PCR for a 300bp rRNA fragment. Specimens were sampled in seven vegetation types, during dry and rainy seasons. The chytrid fungus was detected in Charadrayla taeniopus and Leptodactylus fragilis, species that were not previously recorded with the fungus; the $\mathrm{Bd}$ also was confirmed on amphibians that inhabit from perennial rainforest at southeastern Mexico. According to CARTs, host species and precipitation were the most important factor to $\mathrm{Bd}$ occurrence but their combination with other variables as development stage, environmental temperature, season, vegetation type and aquatic life index have influence on its presence. In addition, the tadpoles had 1.52 times more prevalence of Bd than adults, and that tadpoles from two amphibian species studied could be reservoirs potentially. Although no amphibian showed clinical signs of chytridiomycosis, our findings indicate that the presence and persistence of $\mathrm{Bd}$ may be related with species susceptibility or resistance and interaction of diverse abiotic and biotic factors.
\end{abstract}

Key words: Seasonality; nested PCR; tadpoles; aquatic life index; Specie Distribution Model; CART

\title{
INTRODUCCIÓN
}

La diversidad y densidad de anfibios a nivel mundial han disminuido rápidamente en las últimas dos décadas, donde la infección por Batrachochytrium dendrobatidis (quitridiomicosis) ha sido un factor importante (Daszak et al., 2003; Stuart et al., 2004; IUCN, 2017). La severidad de los cambios ambientales recientes y la rápida dispersión que favorecen las epizootias de anfibios apoyan la hipótesis del patógeno endémico, la cual sugiere que dicho patógeno ha estado siempre presente y ha incrementado su rango de hospederos y/o patogenicidad (Stuart et al., 2004; Rachowicz et al., 2005; Pounds et al., 2006; Kilpatrick et al., 2010; Slenning, 2010). No obstante, recientemente se han encontrado evidencias de la hipótesis del patógeno invasor de un solo origen (O’Hanlon et al., 2018).

Existen condiciones ambientales (p.e. temperatura y humedad) y características del hábitat (p.e. tipo de vegetación) que determinan la presencia, supervivencia y reproducción de los organismos (Sinclair et al., 2006). En el caso de Batrachochytrium dendrobatidis (Bd), algunos experimentos demostraron que la resistencia/susceptibilidad del hongo quítrido depende de la temperatura (Berger et al., 2004; Andre et al., 2008). Se ha determinado que los cultivos purificados de hongos quitridios tienen altas tasas de crecimiento entre $16^{\circ} \mathrm{C} \mathrm{y} 23^{\circ} \mathrm{C}$, pero crecen lentamente a temperaturas entre $4^{\circ} \mathrm{C}$ y $16^{\circ} \mathrm{C}$ (Longcore et al., 1999; Berger et al., 2004). Las bajas temperaturas proporcionan condiciones favorables para su crecimiento mientras los hospederos se encuentran en hibernación (Piotrowski et al., 2004; Johnson y Speare, 2005) y/o los anfibios reducen su inmunidad (Berger et al., 2004). Aunque el hongo quítrido crece más lentamente a temperaturas superiores a $28^{\circ} \mathrm{C}$, se han producido brotes en climas templados durante la temporada más cálida en las zonas montañosas frías (Bosch et al., 2001) o durante el invierno en tierras bajas cálidas (Bradley et al., 2002). La prevalencia de Bd es alta durante los períodos de temperatura fría (Berger et al., 2004; Woodhams y Alford, 2005; Kriger y Hero, 2007), mostrando una aparente estacionalidad en zonas templadas o presentándose en áreas tropicales frías (Bradley et al., 2002).

Batrachochytrium dendrobatidis ha sido identificado en 74 especies de anfibios ubicadas principalmente en el centro y sur de México, entre los 338 y los 3236 msnm (Frías-Álvarez et al., 2008; Mendoza-Almeralla et al., 2015; López-Velázquez, 2018). No obstante, la presencia del hongo quítrido 
aumentan con la altitud (Berger et al., 1998; Bosch et al., 2001; Weldon et al., 2004; Lips et al., 2006; Rachowicz et al., 2005; Kriger y Hero, 2008) considerando que ocurre en sitios por encima de los $400 \mathrm{msnm}$ (Whitfield et al., 2012), ya que la temperatura disminuye según la altitud (Bustamante et al., 2010). Además, la temporalidad afecta la prevalencia de $\mathrm{Bd}$, que varía desde una menor prevalencia en la temporada cálida a una mayor prevalencia en la temporada más fresca (Whitfield et al., 2012). Aunque, algunos autores han manifestado que los renacuajos pueden mantener el Bd por largos periodos en sus estructuras bucales durante la temporada seca hasta que realicen su metamorfosis (Woodhams y Alford, 2005; Smith et al., 2007; Longo y Burrowes, 2010), otros mencionan que existe una disminución de la queratina en las estructuras bucales antes de la metamorfosis, pero los hongos quítridos pueden pasar de éstas a la primera queratinización de la piel en las patas diseminándose rápidamente (Marantelli et al., 2004). Asimismo, las características fisicoquímicas del agua son factores que puede influir en la prevalencia de $\mathrm{Bd}$ (Gründler et al., 2012).

La presencia y prevalencia de Bd está influenciada por numerosos factores ambientales, así como las características intrínsecas de los anfibios (Gründler et al., 2012). En México, dos estudios han considerado los factores bióticos y abióticos en la presencia de Bd a lo largo de un gradiente de usos de suelo por agroecosistemas (Murrieta-Galindo et al., 2014; Hernández-López et al., 2018), pero no consideraron a las especies de anfibios como un factor de predisposición. En el presente estudio, evaluamos si cinco factores abióticos (altitud, precipitación, temperatura media y humedad media de las temporada seca y lluviosa) y cuatro variables bióticas (especies de anfibios, estado de desarrollo, índice de vida acuática y tipo de vegetación) o sus interacciones están relacionadas con la presencia de Bd en anfibios mexicanos, como un acercamiento no paramétrico de un modelo de distribución de especies.

\section{MATERIALES Y MÉTODOS}

Sitios de estudio. El muestreo se realizó en diferentes localidades considerando los tipos de vegetación caducifolia, bosque de encino, bosque de pino, áreas de vegetación xerófila y humedales naturales en el centro de México (Ciudad de México, Estado de México, Puebla y Morelos), bosque mesófilo de montaña (BMM) en el centro de Veracruz, y selva alta perennifolia (SAP) de Tabasco en el sureste de México. Estas localidades se distribuyeron entre los $200 \mathrm{msnm}$ y los $2800 \mathrm{msnm}$, pero no en un gradiente altitudinal (Cuadro 1). Para los sitios, se consideró la temporalidad ambiental reportadas para México (CONAGUA 2011), la cual se registra que la temporada seca va de noviembre a mayo y la temporada lluviosa de junio a octubre. Las temperaturas ambientales promedio, la precipitación y la humedad relativa para cada temporada fueron obtenidas de los registros nacionales (CONAGUA 2011).

Colecta de hisopados cutáneos y orales. Capturamos al azar cualquier anfibio durante la temporada seca (noviembre de 2010 a mayo de 2011) y la temporada lluviosa (junio a octubre de 2011). Algunas localidades fueron visitadas en ambas temporadas climáticas, mientras que otras solo en una temporada debido a que los anfibios no estaban presentes, era difícil la captura o era difícil el acceso a los sitios. Todos los anfibios fueron capturados utilizando una red de malla fina, y fueron manipulados con guantes de látex estériles para evitar la contaminación de la muestra y reducir el riesgo de transmisión del Bd a través de la contaminación cruzada entre individuos. Las redes se lavaron con cloro al 5\% y enjuagadas con agua limpia entre capturas. La obtención de muestras se realizó de acuerdo con la metodología descrita por Kriger et al. (2006), utilizando individualmente hisopos de rayón estériles (Medical Wire and Equipment, MW 100-100, Biomerieux). Cada hisopo fue frotado con firmeza, pero con suavidad, de manera que quedara impregnado con el exudado cutáneo. Se frotó diez veces en el dorso del animal, diez veces en los flancos del tórax, diez veces en el vientre, diez veces en la superficie ventral del muslo y cinco veces en las superficies palmar y plantar de cada pata. Las muestras de hisopos se obtuvieron de todos los individuos adultos capturados, a pesar de la presencia o ausencia de signos clínicos o lesiones dérmicas macroscópicas que sugirieran quitridiomicosis (según Berger et al., 1998 y Nichols et al., 2001). Las muestras de hisopos de renacuajos 
García-Feria et al.: Determinantes para la presencia de Batrachochytrium dendrobatidis en anfibios

se tomaron de las estructuras bucales de todos los individuos capturados, independientemente de los signos de quitridiomicosis reportados como pérdida de tejido, daño dérmico, lesiones o decoloración de las estructuras bucales (según Rachowicz, 2002), ya que estas estructuras se pueden perder o dañar debido a otros factores durante la metamorfosis (etapas 40-42), y dichos signos pueden confundirse con lesiones de quitridiomicosis (Gosner, 1960; Lips et al., 2004). Los hisopos se conservaron en crioviales con $150 \mu 1$ de buffer de lisis (Longmire et al., 1997) a temperatura ambiente, hasta su almacenamiento en laboratorio (dentro de las cuatro horas posteriores a la colecta), donde se almacenaron a $-20^{\circ} \mathrm{C}$ hasta su procesamiento. Tanto los adultos como los renacuajos fueron recolectados y muestreados de cuerpos de agua permanentes. Las muestras de adultos obtenidas de cuerpos de agua temporales se adquirieron en la localidad de la selva alta perennifolia, ubicados a $100 \mathrm{~m}$ de fuentes de agua permanentes. Cada individuo fue fotografiado para la identificación de las especies y si presentaban lesiones dérmicas. Los especímenes fueron liberados en el mismo sitio donde fueron capturados. Además, fueron consideradas muestras de individuos de Ambystoma mexicanum, los cuales se encontraban en tanques mantenidos a la intemperie a los que se les proveía de agua de los canales del lago de Xochimilco sin ningún tratamiento previo; estos individuos fueron considerados del ambiente humedal, debido al uso directo del agua del lago.

Cuadro 1. Tipo de vegetación, temperatura y humedad de los sitios de colecta de diferentes especies de anfibios para la detección de la presencia de Batrachochytrium dendrobatidis. $\mathrm{n}=$ número de individuos examinados; $\mathrm{n}+=$ número de individuos positivos a $\mathrm{Bd} ;{ }^{\circ} \mathrm{C}=$ Temperatura ambiental promedio; $\mathrm{HR}=$ porcentaje de humedad relativa promedio.

\begin{tabular}{|c|c|c|c|c|c|c|c|c|c|c|c|c|c|}
\hline \multirow[t]{2}{*}{ Vegetación $^{a}$} & \multicolumn{3}{|c|}{ Ubicación } & \multirow{2}{*}{ Especies $^{b}$} & \multirow{2}{*}{ Distribución $^{c}$} & \multicolumn{4}{|c|}{ Temporada seca } & \multicolumn{4}{|c|}{$\begin{array}{c}\text { Temporada } \\
\text { lluviosa }\end{array}$} \\
\hline & msnm & $\mathbf{N}$ & $\mathbf{O}$ & & & $\mathbf{n}$ & $\mathbf{n +}$ & ${ }^{\circ} \mathbf{C}$ & HR & $\mathbf{n}$ & n+ & ${ }^{\circ} \mathbf{C}$ & HR \\
\hline \multirow{6}{*}{ BMM } & 1259 & $19^{\circ} 29^{\prime} 27^{\prime \prime}$ & $96^{\circ} 56^{\prime} 48^{\prime \prime}$ & Rhmi & $\mathrm{E}$ & 47 & 22 & 16.8 & 55 & 45 & 33 & 20.8 & 95 \\
\hline & 1449 & $19^{\circ} 03^{\prime} 00^{\prime \prime}$ & $96^{\circ} 59^{\prime} 09^{\prime \prime}$ & Chta & $\mathrm{E}$ & 3 & 2 & 16.8 & 55 & 2 & 2 & 20.8 & 95 \\
\hline & 1256 & $19^{\circ} 27^{\prime} 37^{\prime \prime}$ & $96^{\circ} 59^{\prime} 23^{\prime \prime}$ & Hyfl & $\mathrm{NE}$ & & & & & 2 & 2 & 20.8 & 95 \\
\hline & 1449 & $19^{\circ} 03^{\prime} 00^{\prime \prime}$ & $96^{\circ} 59^{\prime} 09^{\prime \prime}$ & Eleu & $\mathrm{NE}$ & 1 & 1 & 16.8 & 55 & & & & \\
\hline & 1314 & $19^{\circ} 30^{\prime} 58^{\prime \prime}$ & $96^{\circ} 53^{\prime} 27^{\prime \prime}$ & Libe & $\mathrm{NE}$ & 2 & 2 & 16.8 & 55 & & & & \\
\hline & 1045 & $19^{\circ} 24^{\prime} 01^{\prime \prime}$ & $96^{\circ} 58^{\prime} 33^{\prime \prime}$ & $\mathrm{R}-R h m i$ & $\mathrm{E}$ & 32 & 26 & 16.8 & 55 & 13 & 11 & 20.8 & 95 \\
\hline \multirow{5}{*}{ Xerófila } & 1995 & $18^{\circ} 54^{\prime} 19^{\prime \prime}$ & $98^{\circ} 04^{\prime} 21^{\prime \prime}$ & Lisp & $\mathrm{E}$ & 9 & 0 & 17.5 & 43 & 16 & 11 & 18.5 & 63 \\
\hline & & & & $\mathrm{R}-L i s p$ & $\mathrm{E}$ & 13 & 6 & 17.5 & 43 & 17 & 14 & 18.5 & 63 \\
\hline & 1316 & $18^{\circ} 12^{\prime} 29^{\prime \prime}$ & $97^{\circ} 54^{\prime} 22^{\prime \prime}$ & Lisp & $\mathrm{E}$ & & & & & 8 & 0 & 19.4 & 45 \\
\hline & & & & Hyar & $\mathrm{NE}$ & 2 & 0 & 17.5 & 43 & 9 & 3 & 19.4 & 45 \\
\hline & & & & Spmu & $\mathrm{NE}$ & & & 17.5 & 43 & 1 & 0 & 19.4 & 45 \\
\hline \multirow{2}{*}{ Decidua } & 861 & $18^{\circ} 19^{\prime} 39^{\prime \prime}$ & $98^{\circ} 50^{\prime} 02^{\prime \prime}$ & Eleu & $\mathrm{NE}$ & & & & & 1 & 0 & 21.5 & 50 \\
\hline & & & & Hyar & $\mathrm{NE}$ & & & & & 1 & 0 & 21.5 & 50 \\
\hline \multirow{3}{*}{ Bosque de encino } & 2627 & $19^{\circ} 40^{\prime} 14^{\prime \prime}$ & $99^{\circ} 31^{\prime} 24^{\prime \prime}$ & Hyex & $\mathrm{E}$ & & & & & 16 & 1 & 17 & 70 \\
\hline & & & & Hyar & $\mathrm{NE}$ & & & & & 1 & 1 & 17 & 70 \\
\hline & & & & Sрти & $\mathrm{NE}$ & & & & & 3 & 0 & 17 & 70 \\
\hline Humedal & 2240 & $19^{\circ} 16^{\prime} 57^{\prime \prime}$ & 9906'09" & Amme & $\mathrm{E}$ & 12 & 9 & 18.4 & 31 & & & & \\
\hline \multirow{2}{*}{ Bosque de pino } & 2817 & $19^{\circ} 02^{\prime} 55^{\prime \prime}$ & $99^{\circ} 18^{\prime} 52^{\prime \prime}$ & Lisp & $\mathrm{E}$ & 3 & 0 & 22 & 65 & 3 & 3 & 12 & 90 \\
\hline & & & & $\mathrm{R}-L i s p$ & E & 5 & 1 & 22 & 65 & 11 & 8 & 12 & 90 \\
\hline \multirow{3}{*}{ SAP } & 223 & $17^{\circ} 16^{\prime} 16^{\prime \prime}$ & $91^{\circ} 18^{\prime} 51^{\prime \prime}$ & Rhho & $\mathrm{NE}$ & & & & & 1 & 0 & 28.2 & 90 \\
\hline & & & & Lefr & $\mathrm{NE}$ & & & & & 8 & 2 & 28.2 & 90 \\
\hline & & & & Smba & $\mathrm{NE}$ & & & & & 7 & 3 & 28.2 & 90 \\
\hline
\end{tabular}

${ }^{a}$ BMM.- Bosque mesófilo de montaña; SAP.- Selva alta perennifolia.

${ }^{\mathrm{b}}$ Rhmi.- Rheohyla miotympanum; Chta.- Charadrahyla taeniopus; Hyfl.- Hyalinobatrachium fleischmanni; Eleu.Eleutherodactylus sp.; Libe.- Lithobates berlandieri; R-Rhmi - Renacuajos de R. miotympanum; Lisp.- Lithobates spectabilis; R-Lisp. - Renacuajos de L. spectabilis; Hyar.- Hyla arenicolor; Spmu.- Spea multiplicata; Hyex.- Hyla eximia; Amme.- Ambystoma mexicanum; Rhho.- Rhinella horribilis; Lefr.- Leptodactylus fragilis; Smba.- Smilisca baudinii.

${ }^{\mathrm{c}}$ E.- Especie endémica; NE.- Especie no endémica. 
Extracción de ADN y diagnóstico molecular. La extracción del DNA se realizó siguiendo la metodología sugerida por Miller et al. (1988) y la recomendada por el fabricante del kit de extracción GF-1 (Vivantis Technologies Sdn. Bhd. Malaysia). La amplificación de los fragmentos de $300 \mathrm{pb}$ de RNA ribosómico (rRNA) se realizó mediante un proceso anidado de reacción en cadena de la polimerasa (nPCR) (Goka et al., 2009). El nPCR tiene una mayor sensibilidad cuando se trabaja con bajas cantidad de ácidos nucleicos (Ma et al., 2003; Kawada et al., 2004; Goka et al., 2009) o cuando hay una dilución de los ácidos nucleicos en el proceso de extracción (Ma et al., 2003). En el primer ensayo, la región 18S rRNA de Bd se amplificó usando el oligonucleótido Bd18SF1 (5'-TTTGTACACACCGCCCGTCGC-3') y la región 28S rRNA mediante el oligonucleótido Bd28SR1 (5'-ATATGCTTAAGTTCAGCGGG-3'). En el segundo ensayo, se amplificó a partir de los primeros productos, la región 5.8 del gen rRNA, y las regiones ITS1 e ITS2, usando los oligonucleótidos Bd1a (5'-CAGTGTGCCATATGTCACG-3') y $\quad$ Bd2a $\quad$ (5'CATGGTTCATATCTGTCCAG-3').

Las PCR se realizaron en reacciones de $20 \mu \mathrm{L}$, las cuales incluyeron $2 \mu \mathrm{L}$ de la extracción de ADN, $0.5 \mathrm{mM}$ de cada dNTP, $2 \mathrm{mM}$ de $\mathrm{MgCl}_{2}, 0.25 \mathrm{U}$ de DNA polimerasa Taq (Amplificasa, Biotecnologías Universitarias, FMVZ-UNAM) y $0.5 \mathrm{mM}$ de cada oligonucleótido. La primera reacción se mantuvo durante 9 minutos a $95^{\circ} \mathrm{C}$ con el fin de obtener la desnaturalización inicial. Posteriormente, se corrieron 30 ciclos de 30 segundos a $94^{\circ} \mathrm{C}, 30$ segundos a $50^{\circ} \mathrm{C}$ y 2 minutos a $72^{\circ} \mathrm{C}$ y una extensión final de 7 minutos a $72^{\circ} \mathrm{C}$. Para la segunda amplificación, la desnaturalización inicial se realizó durante 9 minutos a $95^{\circ} \mathrm{C} ; 30$ ciclos de 30 segundos a $94^{\circ} \mathrm{C}, 30$ segundos a $65^{\circ} \mathrm{C}$ y 30 segundos a $72^{\circ} \mathrm{C}$ y una extensión final de 7 minutos a $72^{\circ} \mathrm{C}$.

Se incluyeron controles positivos y negativos en cada amplificación de PCR; los controles positivos se extrajeron de un cultivo de Bd (cepa JEL-423), y el control negativo fue agua estéril destilada libre de ácidos nucleicos. Cada muestra se probó por triplicado para verificar los resultados de cualquier amplificación y para descartar cualquier falso negativo. Los productos de PCR se separaron por electroforesis en geles de agarosa al $2 \%$ y se tiñeron con bromuro de etidio para hacer que las bandas de fragmentos fueran visibles bajo luz UV. Todas las pruebas diagnósticas se realizaron en el Laboratorio de Micología de la Facultad de Medicina Veterinaria y Zootecnia (FMVZ) de la Universidad Nacional Autónoma de México (UNAM).

Análisis de datos. La prevalencia se calculó a partir del número de casos positivos dividido por el número total de muestras; estos incluyen la prevalencia calculada para individuos adultos de cada especie de anfibio capturada, así como para los renacuajos; también el intervalo de confianza al $95 \%$ ajustado para proporciones (Heumann et al., 2016). Una tabla de contingencia evaluada con una prueba de Chi-cuadrada de Pearson con corrección de Yates (Gotelli y Ellison, 2004) fue realizada con el programa Epidat 3.1 (www.sergas.es) para identificar la independencia o asociación de las condiciones (adulto y renacuajo, y temporadas climáticas) hacia la presencia del Bd. Previamente, los datos de presencia se transformaron por la raíz cuadrada de $\mathrm{N}+0.5$, donde $\mathrm{N}$ es presencia (1) o ausencia (0) (Gotelli y Ellison, 2004).

También se realizaron dos árboles de clasificación binomial y de regresión (CART, Breiman et al., 1984) como un enfoque no paramétrico de un modelo de distribución y de preferencia de hábitat (Bell 1996; Vayssières et al., 2000) para evaluar la combinación de nueve variables que podrían determinar la presencia de Bd en anfibios. En el primer CART se consideraron (1) las especies de anfibios (incluidas dos especies de renacuajos como entidades), (2) tipo de vegetación, (3) altitud, (4) temperatura media ambiental, (5) humedad relativa, (6) precipitación, (7) temporada (lluviosa o seca), y (8) un índice de vida acuática (valores tomados de Hernández-López et al., 2018), el cual considera el promedio de valores asignados para cada etapa de desarrollo ([a] larva, [b] adulto en reproducción y [c] adulto en no reproducción); cada etapa toma valores de 1 cuando larvas y adultos tienen hábitos terrestres, 2 cuando los adultos tienen hábitos arborícolas y 3 cuando larvas y adultos son exclusivamente acuáticos (Lips et al., 2003; Hernández-López et al., 2018). El segundo CART se realizó para corregir el posible error debido al tamaño de muestra inferior a 59 (según Skerrat et al., 2008 y Gray et al., 2017), para lo que excluimos la entidad de las especies y la sustituimos 
García-Feria et al.: Determinantes para la presencia de Batrachochytrium

dendrobatidis en anfibios

por el estado de desarrollo (adultos y renacuajos) como variable explicativa. Para el CART, las variables explicativas obtienen un valor de probabilidad de acuerdo con la partición recursiva que divide las variables jerárquicamente por medio de nodos y ramas definidas (Breiman et al., 1984; Vayssières et al., 2000; Gotelli y Ellison, 2004). La selección del árbol con el número de ramas más apropiado para evitar el sobreajuste, se realizó con el cálculo de la tasa de error por la validación cruzada considerado la devianza mínima (Bell, 1996). Los CART se construyeron con el paquete tree (versión 1.0-35) en el programa RStudio v 1.1.463 (R studio, Inc. www.rstudio.com), considerando un valor significativo de 0.05 .

\section{RESULTADOS}

Se tomaron muestras de 203 anfibios adultos de 13 especies mexicanas, que se distribuyeron en siete tipos de hábitats diferentes entre los $223 \mathrm{msnm}$ hasta los $2817 \mathrm{msnm}$ (Cuadro 1). La prevalencia de Bd en los anfibios adultos fue 47.78\% (Cuadro 2). Las muestras de hisopos recogidos de Ambystoma mexicanum en semicautiverio mostraron un $75 \%$ de positivos (9/12) para el hongo quítrido mediante el diagnóstico de nPCR (Cuadro 3). De las muestras colectadas en la selva alta perennifolia (SAP) del sureste de México, cinco de 16 muestras fueron positivas ( $31.25 \%$ de prevalencia), incluyendo anuros fosoriales (Leptodactylus fragilis, $\mathrm{n}=8$ ) y anuros de sotobosque (Smilisca baudinii, $\mathrm{n}=7$ ); estos registros de Bd fueron los primeros reportados a Tabasco y a la región de la Península de Yucatán. Ningún anfibio exhibió lesiones macroscópicas o signos clínicos de enfermedad sugestiva de quitridiomicosis, ni se encontró mortalidad masiva de individuos.

Cuadro 2. Prevalencia de Batrachochytrium dendrobatidis según el estado de desarrollo y temporadas climaticas. $\mathrm{N}$ = número de individuos examinados; $\mathrm{N}+=$ número de individuos positivos a $\mathrm{Bd}$.

\begin{tabular}{|c|c|c|c|c|c|}
\hline Variable & Factor & $\mathbf{N}$ & $\mathbf{N +}$ & $\begin{array}{c}\text { Prevalencia } \\
(\%)\end{array}$ & IC95\%* \\
\hline \multirow{3}{*}{ Estado de desarrollo } & Adultos & 203 & 97 & 47.78 & \pm 6.87 \\
\hline & Renacuajos & 91 & 66 & 72.53 & \pm 9.17 \\
\hline & Total & 294 & 163 & 55.44 & \pm 5.68 \\
\hline \multirow{3}{*}{ Temporada climática } & Temporada seca & 129 & 69 & 53.49 & \pm 8.61 \\
\hline & Temporada lluviosa & 165 & 94 & 56.97 & \pm 7.55 \\
\hline & Total & 294 & 163 & 55.44 & \pm 5.68 \\
\hline \multirow{3}{*}{ Adultos } & Temporada seca & 79 & 36 & 45.57 & \pm 10.98 \\
\hline & Temporada lluviosa & 124 & 61 & 49.19 & \pm 8.80 \\
\hline & Total & 203 & 97 & 47.78 & \pm 6.87 \\
\hline \multirow{3}{*}{ Renacuajos } & Temporada seca & 50 & 33 & 66.00 & \pm 13.13 \\
\hline & Temporada lluviosa & 41 & 33 & 80.49 & \pm 12.13 \\
\hline & Total & 91 & 66 & 72.53 & \pm 9.17 \\
\hline
\end{tabular}

*IC95\% = Intervalo de confianza al 95\% calculado para proporciones (Heumann et al., 2016).

Además, se capturaron 91 renacuajos de los cuales 66 fueron positivos a Bd en la PCR anidada ( $72.53 \%$ de prevalencia; IC95\% = 9.17) (Cuadro 2). La tabla de contingencia mostró que la presencia de Bd está asociada a la etapa de desarrollo de los anfibios (adulto o renacuajo) $\left(X^{2}\right.$ Pearson $=14.57, \mathrm{~g} .1 .=1, \mathrm{P}=$ 0.0001). La proporción de las prevalencias entre renacuajos: adultos indicó que los renacuajos tienen 52\% más prevalencia de Bd que los adultos.

La prevalencia total de $\mathrm{Bd}$ no está asociada a la temporada climática $\left(X^{2}\right.$ Pearson $=0.23$, g. $1 .=1, \mathrm{P}=$ 0.633), siendo de $53.49 \%$ en la temporada seca y de $56.97 \%$ en la temporada lluviosa. El mismo análisis se dividió por etapas de desarrollo, pero no se encontraron asociaciones de la presencia de Bd en las muestras de adultos entre las temporadas climáticas (adultos: $X^{2}{ }_{\text {Pearson }}=0.129$, g. $\left.1 .=1, P=0.719\right)(45.57 \%$ de 
prevalencia en la temporada seca y $49.19 \%$ en la temporada lluviosa). La prevalencia de quitridios en renacuajos fue del $66 \%$ en la temporada seca (33/50) y del $80.49 \%$ durante la temporada lluviosa (33/41); no obstante, la prevalencia no estuvo asociada a la temporada (renacuajos: $X^{2}$ Pearson $=1.702, \mathrm{~g} .1 .=1, \mathrm{P}=$ 0.192) (Cuadro 2).

\section{Análisis multivariado}

La presencia de $\mathrm{Bd}$ en los anfibios está influenciada por la interacción de múltiples variables simultáneamente. El primer árbol de clasificación y regresión realizado a partir de un modelo completo de ocho variables (especies de anfibios [incluidos los renacuajos como una entidad], índice de vida acuática, tipo de vegetación, altitud, temperatura y humedad ambiental, precipitación y temporada) utilizado para predecir la presencia de $\mathrm{Bd}$. En este árbol fueron excluidas las especies que tuvieron menos de siete colectas en los muestreos; únicamente se consideraron siete especies de anfibios (Rheohyla miotympanum, Lithobates spectabilis, Hyla eximia, Hyla arenicolor, Leptodactylus fragilis, Smilisca baudinii y Ambystoma mexicanum) y dos de renacuajos ( $R$. miotympanum y L. spectabilis). El árbol resultante generó siete divisiones y ocho nodos terminales a partir de cuatro variables seleccionadas (especies, precipitación, temperatura y temporada climática). El modelo de CART más preciso fue elegido por la menor tasa de error de clasificación obtenida con la validación cruzada $(0.24=68 / 278)$ (Fig. 1). El árbol resolvió con un 94\% de probabilidad que Bd estuviera presente en individuos adultos de Hyla arenicolor, Lithobates spectabilis y Smilisca baudinii cuando estas especies viven a temperaturas ambientales inferiores a $20.25^{\circ} \mathrm{C}$ y precipitaciones superiores a $22.5 \mathrm{~mm}$. El modelo CART también considera que Ambystoma mexicanum y renacuajos de Rheohyla miotympanum son más propensos a la presencia de $\mathrm{Bd}$ per se $(\mathrm{P}=0.81)$, así como adultos de $R$. miotympanum y renacuajos de Lithobates spectabilis, pero durante la temporada lluviosa la probabilidad de presencia de $\mathrm{Bd}$ aumenta $(\mathrm{P}=0.75)$ (Fig. 1).

El segundo CART también se incluye ocho variables, pero en lugar de la variable 'especie' consideramos el estado de desarrollo (adulto o renacuajo), esto para corregir el posible error debido al tamaño de muestra de algunas especies. En este análisis se contaron con 91 muestras de renacuajos y fueron incluidas 203 muestras de individuos adultos de 13 especies (Cuadro 3). El modelo más preciso también fue seleccionado de acuerdo con la menor tasa de error de clasificación obtenida con la validación cruzada $(0.2313=68 / 294)$. El árbol de regresión generado tuvo cinco divisiones y seis nodos terminales para cinco variables seleccionadas (precipitación, tipo de vegetación, temperatura e índice de vida acuática) (Fig. 2). En el CART se observa que el hongo quítrido podría estar presente en anfibios adultos y renacuajos del $\mathrm{BMM}$, del bosque de pino, los humedales y de la vegetación xerófila cuando se presentan precipitaciones mayores a $10 \mathrm{~mm}$, la temperatura ambiental esté por debajo de $\operatorname{los} 21.75^{\circ} \mathrm{C}$ y presentan un índice de vida acuática mayor a $2.50(\mathrm{P}=0.79)$. Además, $\mathrm{Bd}$ también puede estar presente con $72 \%$ de probabilidad en adultos y larvas con índice de vida acuática por abajo de 2.50 , cuando la temperatura ambiental este por arriba de los $16.9^{\circ} \mathrm{C}$ (Fig. 2).

\section{DISCUSIÓN}

En diferentes regiones del mundo, la quitridiomicosis se ha asociado con la mortalidad en masa de muchas poblaciones de anfibios (Laurence, 1996; Laurence et al., 1997; Berger et al., 1998; Longcore et al., 1999; Bosch et al., 2001; Daszak et al., 2003; Lips et al., 2004; Pounds et al., 2006; James et al., 2009; Voyles et al., 2009). Sin embargo, la ausencia de signos clínicos también se ha reportado en algunos lugares donde el quítrido se ha detectado (Carnaval et al., 2006; Toledo et al., 2006; Gründler et al., 2012). En este estudio, no encontramos anfibios con lesiones macroscópicas o signos de enfermedad ni eventos de mortalidad masiva por Bd. Nuestros resultados obtenidos a través del análisis de PCR anidado muestran un rango más amplio de valores (de 6 a 100\%) de la presencia de Bd comparado con los porcentajes previamente reportados en México y detectados por PCR en tiempo real (75\%, Lips et al., 2004; 84-100\%, Frías-Álvarez et al., 2008). No obstante, en otros estudios se ha demostrado que la técnica de PCR anidada es más sensible 
García-Feria et al.: Determinantes para la presencia de Batrachochytrium dendrobatidis en anfibios

y específica para detectar fragmentos de ácidos nucleicos, incluso en muestras contaminadas o degradadas (Goka et al., 2007; Gaertner et al., 2009). Posiblemente, la sensibilidad y especificidad de la PCR anidada refleje menores tasas de falsos negativos y tenga alta detección del hongo quítrido.

La presencia del hongo quítrido ha sido reportada en múltiples lugares en México, incluyendo Sonora (Rollins-Smith et al., 2002), Guerrero (Lips et al., 2004; Frías-Álvarez et al., 2008), Chiapas (Quintero-Díaz, 2004; Frías-Álvarez et al., 2008), Ciudad de México, Estado de México, Michoacán, Morelos, Oaxaca, Puebla, Hidalgo y Nuevo León (Frías-Álvarez et al., 2008), y el centro de Veracruz (Murrieta-Galindo et al., 2014). No obstante, se menciona que al menos 74 especies de anfibios, de las familias Hylidae y Plethodontidae, distribuidas en las regiones montañosas del centro y sur de México tienen susceptibilidad a Bd (Mendoza-Almeralla et al., 2015; López-Velázquez, 2018). Todos los registros coinciden en que el hongo quítrido ocurre en altitudes superiores a $600 \mathrm{msnm}$, y en climas templados y húmedos, pero no se especifican los tipos de vegetación. Murrieta-Galindo et al. (2014) definen que algunas especies de anfibios con reproducción acuática que habitan en el bosque mesófilo de montaña son más susceptibles a la presencia de Bd. En nuestro trabajo, incluimos como nuevo reporte, la presencia del quítrido en la selva alta perennifolia de Tabasco en el sureste de México. La presencia de Bd en este tipo de zonas se ha reportado en zonas tropicales frías (Bradley et al., 2002), sin embargo, en nuestro sitio de muestreo (SAP, Cuadro 1) presenta un clima cálido húmedo con lluvias todo el año y la temperatura más fría se da en enero con $>18.1^{\circ} \mathrm{C}$ (INEGI, 2017). Esta localidad está aproximadamente a $160 \mathrm{~km}$ de la ubicación geográfica más cercana, Pueblo Nuevo, Chiapas (Muñoz-Alonso, 2013), donde se documentó la presencia de $\mathrm{Bd}$. Nuestro hallazgo modifica los registros de altitud y distribución de Bd en tierras bajas de la vertiente del Golfo de México (ver Mendoza-Almeralla et al., 2015).

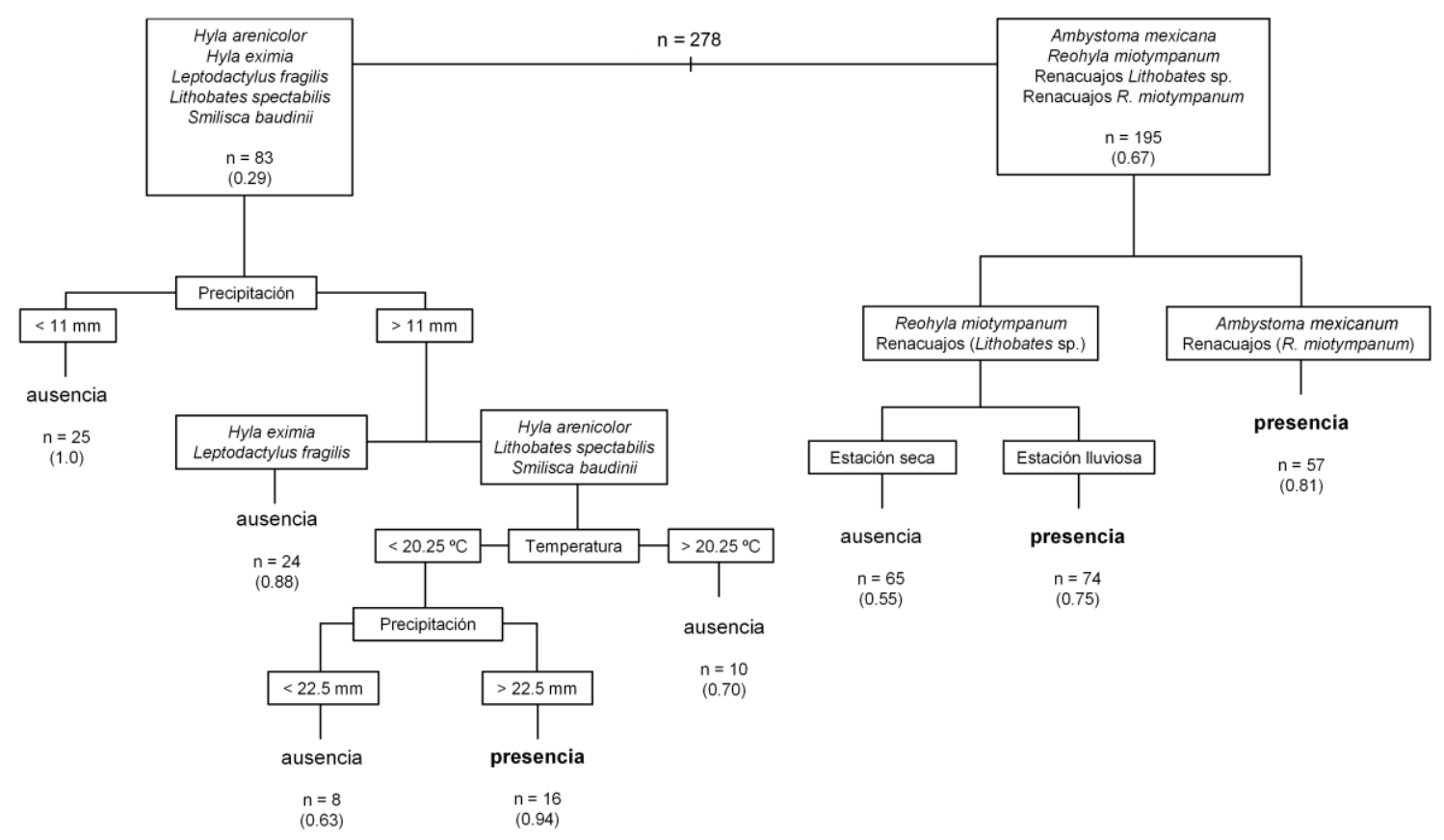

Figura 1. Modelo de predicción de presencia de Batrachochytrium dendrobatidis en 13 especies de anfibios adultos y dos de renacuajos y seis variables ambientales mediante un árbol de clasificación y regresión. 
Algunas de las especies estudiadas en este trabajo son endémicas de México, incluyendo Rheohyla miotympanum, Ambystoma mexicanum, Hyla eximia, Charadrahyla taeniopus y Lithobates spectabilis (IUCN, 2017); documentamos el primer informe de los hallazgos de Bd en C. taeniopus. Las otras ocho especies tienen un amplio rango de distribución en el continente americano, pero no son especies endémicas de México: Hyalinobatrachium fleischmanni, Lithobates berlandieri, Hyla arenicolor, Spea multiplicata, Rhinella horribilis, Leptodactylus fragilis, Smilisca baudinii y Eleutherodactylus sp. También documentamos el primer informe de $\mathrm{Bd}$ en Leptodactylus fragilis, el resto de las especies habían sido reportadas previamente como positivas para la quitridiomicosis en otras localidades mexicanas (Lips et al., 2004; Frías-Álvarez et al., 2008; Muñoz-Alonso, 2013).

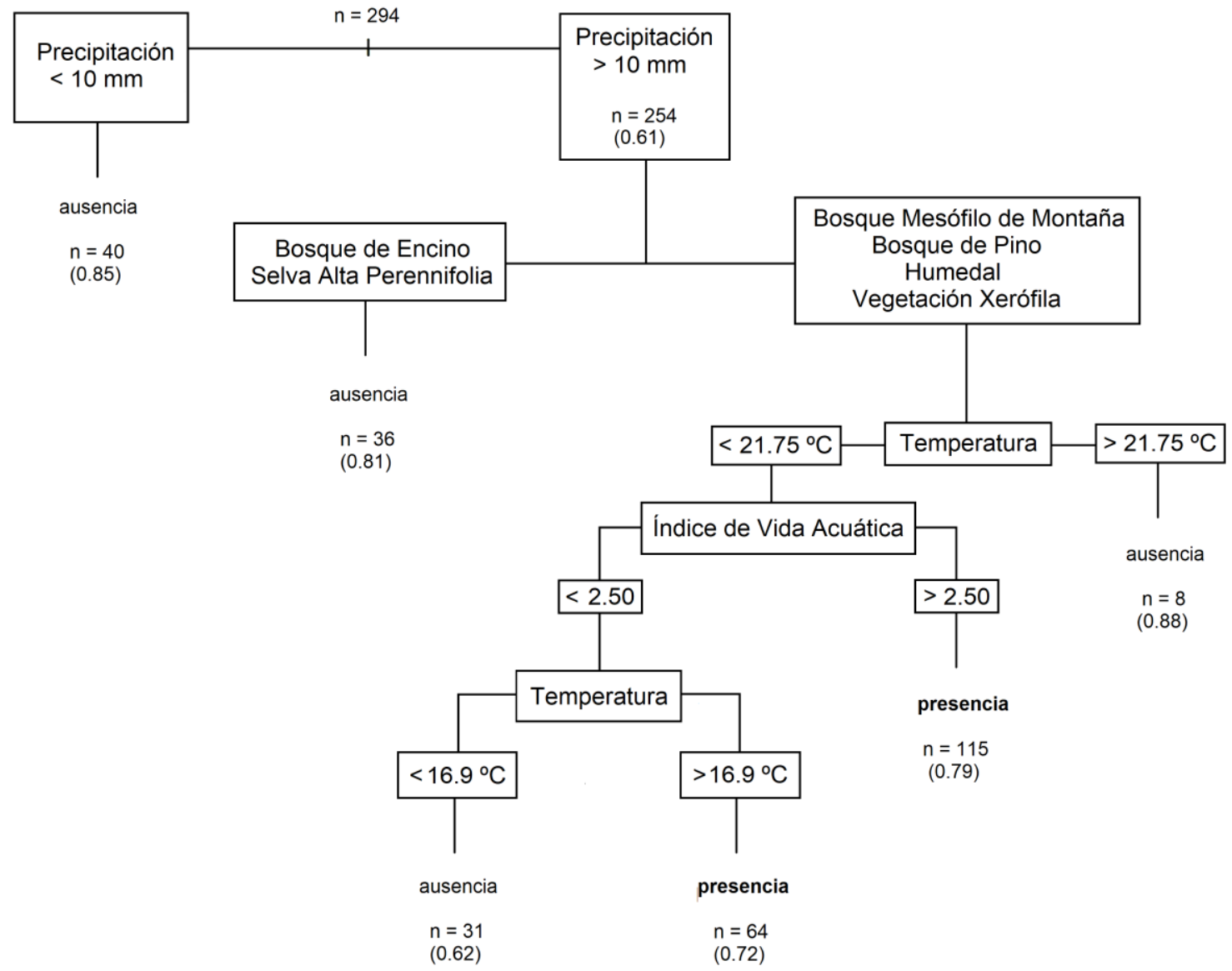

Figura 2. Modelo de predicción de presencia de Batrachochytrium dendrobatidis en anfibios adultos y renacuajos y seis variables ambientales mediante un árbol de clasificación y regresión.

En el lago Xochimilco, los ajolotes (Ambystoma mexicanum) muestreados en el CIBAC en los tanques con agua del lago tuvieron alta prevalencia de $\mathrm{Bd}$, lo que confirma que el hongo quítrido está presente en las vías fluviales de Xochimilco. Esta posibilidad de que Bd esté presente en los pocos ajolotes silvestres ha sido mencionada por Frías-Álvarez et al. (2008), que no pudieron declarar al lago como sitio libre de $\mathrm{Bd}$ debido al tamaño de muestra demasiado pequeño $(\mathrm{N}=2)$. 
García-Feria et al.: Determinantes para la presencia de Batrachochytrium dendrobatidis en anfibios

Los porcentajes de prevalencia de Bd detectados en el presente estudio (47.78\% en adultos) estuvieron dentro del rango reportado en otros trabajos de investigación previos realizados en México (96.4\% por Frías-Álvarez et al., 2008; 21\% por Muñoz-Alonso, 2013; 20\% por Murrieta-Galindo et al., 2014). Además, identificamos una alta prevalencia entre los renacuajos $(72.53 \%)$ en comparación con solo el $17.72 \%$ reportado por Murrieta-Galindo et al. (2014), lo que nuestro resultado refleja una relación de 1.52 veces la prevalencia respecto a la de los adultos. La relación es similar a lo reportado por Longo y Burrowes (2010), quienes estimaron una relación renacuajo: adulto de 1.5. No obstante, reportamos que la mayor prevalencia de Bd está en los renacuajos, ninguno tuvo sin signos clínicos de quitridiomicosis, como es la pérdida de forma de las estructuras orales queratinizadas. Estas alteraciones bucales pueden confundirse entre la quitridiomicosis y la pérdida natural y la maduración por la metamorfosis normal (etapas 40-42, Gosner, 1960; Lips et al., 2004). Se ha sugerido que la alta prevalencia de Bd entre los renacuajos podría indicar que están contribuyendo como reservorios durante períodos prolongados, manteniendo al hongo en la población y en el ambiente hasta que las condiciones ambientales sean óptimas para la metamorfosis (Woodhams y Alford, 2005; Smith et al., 2007). Aunque los renacuajos tienen tejido epidérmico queratinizado insuficiente para permitir la invasión eficiente de los quítridos y su establecimiento, la prevalencia aumenta hasta estados postmetamórficos como subadultos, que también pueden actuar como reservorios (Cashins, 2009; Piova-Scott et al., 2011). Según nuestros hallazgos, confirman que especies con fases adultas acuáticas (i.e. Ambystoma mexicanum) y renacuajos (según el primer CART, Fig. 1) podrían mantener la presencia del quítrido en el ambiente por resistencia (Briggs et al., 2010) o especies que requieren constante presencia en todas sus fases de desarrollo, reflejado en valores de índice de vida acuática altos (p.e. índice de vida acuática $>2.50$, según segundo CART, Fig. 2).

Los agentes etiológicos se manifiestan cuando se da la interacción múltiple y compleja entre las condiciones ambientales, la dinámica de la población, la resistencia del huésped y la virulencia de los patógenos (Voyles et al., 2009). La prevalencia e intensidad tienden a ser bajas en sitios enzoóticos; la reinfección de individuos resistentes podría hacer que el patógeno persista en la población y el medio ambiente (Briggs et al., 2010), aunado con las interacciones de las condiciones bióticas y abióticas (Daszak et al., 2003; Lips et al., 2003; Berger et al., 2004; Rohr y Raffel, 2010). Estas interacciones pueden comprometer estacionalmente la respuesta inmune y el comportamiento del huésped, así como la dinámica parásito-hospedero (Woodhams y Alford, 2005). El presente estudio indica que dentro de las variables analizadas, las más importantes para la presencia de Bd en anfibios silvestres aparentemente sanos fueron la precipitación y la especie de anfibios, sumándose la especificidad del hábitat (i.e., boque mesófilo de montaña, bosque de encino, vegetación xerófila y humedales) o la posible función de reservorio por parte de los renacuajos y de especies con fases adultas de alta asociación con cuerpos de agua (i.e. Ambystoma mexicanum, Lithobates sp., Rheohyla miotympanum) e índices de vida acuática altos. Anteriormente, algunas de estas variables se conocían como parte del riesgo de quitridiomicosis (Lips et al., 2003; Berger et al., 2004; Rohr y Raffel, 2010). En México, Murrieta-Galindo et al. (2014) encontraron una combinación de variables bióticas y abióticas (i.e. densidad de árboles, especies de helechos, temperatura, elevación, tamaño de fragmentos e índice estructural) que se correlacionan positivamente con la infección por Bd en anfibios de agroecosistemas de café en el bosque mesófilo de montaña. En una recopilación de datos de registros publicados, Hernández-López et al. (2018) encuentran que el tipo de desarrollo larvario y factores ambientales tales como temperatura, precipitación y perturbación (p.e. cambios en la vegetación y tipos de uso de suelo), afectan el riesgo de infección por Bd. No obstante, encuentran una asociación negativa entre el grado de perturbación y la tasa de infección. Aunque nosotros no evaluamos el grado de perturbación, nuestros hallazgos concuerdan en que la temperatura y precipitación son importantes, junto con el tipo de desarrollo larvario, en nuestro caso, especies de desarrollo larvario de vida libre (Rheoyla miotympanum y Lithobates sp.).

El gran número de especies de anfibios estudiadas previamente en México, verifica la presencia de Bd distribuido en diferentes hábitats, desde bosques de coníferas hasta bosques tropicales (Rollins-Smith et al., 2002; Lips et al., 2004; Frías-Álvarez et al., 2008; Luja et al., 2012, Murrieta-Galindo et al., 2014; 
Mendoza-Almeralla et al., 2015), en altitudes entre los $338 \mathrm{~m}$ y más de 3,000 $\mathrm{m}$ sobre el nivel del mar (Frías-Álvarez et al., 2008). Las áreas más bajas registradas en este trabajo con la presencia de Bd se encontraron en la selva alta perennifolia (SAP) a $223 \mathrm{msnm}$. Al igual que en el bosque mesófilo de montaña, la SAP también presenta mayor humedad $(>90 \%)$ por tener un clima cálido húmedo con lluvias todo el año (INEGI 2017); sin embargo, SAP experimenta una temperatura anual promedio más alta $\left(28.2^{\circ} \mathrm{C}\right)$ que los otros tipos de vegetación evaluados. En las selvas altas del sureste de México, la prevalencia de Bd fue mayor (31.25\%) que el 19.8 por ciento reportado en estudios previos en el mismo tipo de vegetación en la amazonia ecuatoriana, ubicados entre $190 \mathrm{~m}$ y $250 \mathrm{msnm}$ con una temperatura promedio de $25^{\circ} \mathrm{C}$ (McCracken et al., 2009). Además, nuestros resultados también exceden la prevalencia reportada en los bosques tropicales de Costa Rica (entre $100 \mathrm{~m}$ y $399 \mathrm{msnm}$ ), que presentan una prevalencia del quítrido del 17.6\% (Puschendorf et al., 2006).

Cuadro 3. Prevalencia de Batrachochytrium dendrobatidis por temporada climatica e indice de vida acuatica de 13 especies de anfibios adultos y dos especies de renacuajos. $\mathrm{N}=$ número de individuos examinados; IVA = Índice de vida acuática; $\mathrm{n}=$ número de individuos en cada temporada climática; $\mathrm{n}+=$ número de individuos positivos a $\mathrm{Bd}$ en cada temporada climática; Prev $=\%$ de prevalencia.

\begin{tabular}{|c|c|c|c|c|c|c|c|c|}
\hline \multirow{2}{*}{ Especie } & \multirow{2}{*}{$\mathbf{N}$} & \multirow{2}{*}{ IVA* } & \multicolumn{3}{|c|}{ Temporada seca } & \multicolumn{3}{|c|}{ Temporada lluviosa } \\
\hline & & & $\mathbf{n}$ & $\mathbf{n}+$ & Prev & $\mathbf{n}$ & $\mathbf{n +}$ & Prev \\
\hline Rheohyla miotympanum & 92 & 2.33 & 47 & 22 & 46.81 & 45 & 33 & 73.33 \\
\hline Charadrahyla taeniopus & 5 & 2.67 & 3 & 2 & 66.67 & 2 & 2 & 100.00 \\
\hline Hyalinobatrachium fleischmanni & 2 & 2.33 & & & & 2 & 2 & 100.00 \\
\hline Eleutherodactylus sp. & 2 & 1 & 1 & 1 & 100.00 & 1 & 0 & 0.00 \\
\hline Lithobates berlandieri & 2 & 3 & 2 & 2 & 100.00 & & & \\
\hline Lithobates spectabilis & 39 & 3 & 12 & 0 & 0.00 & 27 & 14 & 51.85 \\
\hline Hyla arenicolor & 13 & 2.67 & 2 & 0 & 0.00 & 11 & 4 & 36.36 \\
\hline Spea multiplicata & 4 & 2.33 & & & & 4 & 0 & 0.00 \\
\hline Hyla eximia & 16 & 2.67 & & & & 16 & 1 & 6.25 \\
\hline Ambystoma mexicanum & 12 & 3 & 12 & 9 & 75.00 & & & \\
\hline Rhinella horribilis & 1 & 2.33 & & & & 1 & 0 & 0.00 \\
\hline Leptodactylus fragilis & 8 & 2.33 & & & & 8 & 2 & 25.00 \\
\hline Smilisca baudinii & 7 & 2.67 & & & & 7 & 3 & 42.86 \\
\hline Total & 203 & & 79 & 36 & 45.57 & 124 & 61 & 49.19 \\
\hline Renacuajos de $R$. miotympanum & 45 & 3 & 32 & 26 & 81.25 & 13 & 11 & 84.62 \\
\hline Renacuajos de $L$. spectabilis & 46 & 3 & 18 & 7 & 38.89 & 28 & 22 & 78.57 \\
\hline Total & 91 & & 50 & 33 & 66.00 & 41 & 33 & 80.49 \\
\hline
\end{tabular}

*valores tomados de Hernández-López et al., 2018.

Aunque se ha reportado que la presencia de $\mathrm{Bd}$ puede darse en temperaturas superiores a $\operatorname{los} 25^{\circ} \mathrm{C}$, el hongo no crece y puede morir, nuestros resultados corroboran que puede ser viable a temperaturas mayores como las del sureste mexicano. No obstante, algunos investigadores consideran que las temperaturas inferiores a $25^{\circ} \mathrm{C}$ son óptimas para su crecimiento (Berger et al., 1998; Bosch et al., 2001), también corroboramos con nuestros resultados del CART, que la temperatura por debajo de los $19.9^{\circ} \mathrm{C}$ es óptima para su presencia. Por otro lado, algunos estudios han confirmado que Bd está presente en bajas altitudes (Beard y O'Neal, 2005; Carnaval et al., 2006; Flechas et al., 2012; Luja et al., 2012). Nuestros hallazgos demuestran que el hongo sobrevive con alta prevalencia en selva alta perennifolia en altitudes de $\approx 200 \mathrm{msnm}$, donde la temperatura máxima diaria promedio puede ser de $36^{\circ} \mathrm{C}$ durante la temporada cálida y las temperaturas mínimas están por arriba de $\operatorname{los} 18^{\circ} \mathrm{C}$ (CONAGUA, 2011; INEGI, 2017). Estos resultados demuestran que el hongo quítrido tiene un rango de temperatura más amplio para el crecimiento en condiciones silvestres respecto a las condiciones en laboratorio (Longcore et al., 1999; Berger et al., 2004). Este amplio rango puede hacer que Bd esté presente y pueda causar enfermedad cuando las condiciones 
García-Feria et al.: Determinantes para la presencia de Batrachochytrium

dendrobatidis en anfibios

ambientales afecten la actividad protectora de la microbiota cutánea (Daskin et al., 2014) o al sistema inmune de los anfibios (Woodhams et al., 2008). El rango de temperatura de los hábitats naturales es un factor que requiere una evaluación más profunda para comprender el ciclo natural de la enfermedad y la vulnerabilidad potencial de otras especies de anfibios que anteriormente no se consideraban en riesgo.

No obstante, se ha informado que otros factores de riesgo podrían desempeñar un papel en la presencia de $\mathrm{Bd}$, varios modelos evaluaron las sinergias entre variables como posibles causas del declive de la población mundial de anfibios, como la pérdida de hábitat, el cambio climático, la sobreexplotación, las enfermedades y la pérdida de diversidad de anfibios (Sodhi et al., 2008; Searle et al., 2011). Diferentes combinaciones de estas variables sugieren que las especies de anfibios, especialmente en aquellas con rangos de distribución pequeños y restringidos, con hábitats estacionales en temperatura y precipitación, tienen el mayor riesgo de extinción. En nuestros análisis CART obtuvimos que la especie de anfibio y la precipitación son las variables principales que determinan la presencia de $\mathrm{Bd}$, y se van combinando con el tipo de hábitat, la temperatura y humedad, el estado de desarrollo y el índice de vida acuática. Aunque algunos autores mencionan que el grado de perturbación de la vegetación y el tipo de uso de suelo afecta a la infección por Bd (Hernández-López et al., 2018), otros mencionan que no hay un efecto en la prevalencia en algunos tipos de ecosistemas (i.e. bosque mesófilo de montaña) (Murrieta-Galindo et al., 2014). Sin embargo, la presencia posiblemente se deba a la alta humedad ambiental y a la susceptibilidad o resistencia de las especies al quítrido (i.e. Rheohyla miotympanum), tal como nuestros hallazgos lo demuestran.

En algunos estudios ecológicos, la infección por Bd no fue considerada como la causa directa de muerte y extinción de los anfibios (Burgin et al., 2005; McCallum, 2005). Hay muchas variables que afectan las interacciones de la tríada ecológica: medio ambiente-fauna-ser humano (por ejemplo, la pérdida de hábitat, la contaminación, las especies invasoras, la densidad de población humana, el cambio climático y otras causas desconocidas), e incrementan el riesgo de extinción (Sodhi et al., 2008). Estas presiones disminuyen las poblaciones de anfibios a nivel local, regional y mundial, y pueden predisponer a éstos a brotes de enfermedades. Muchas especies de anfibios están catalogadas por la UICN en diferentes niveles de riesgo, e incluyen los brotes epizoóticos de Bd como una de las causas principales. Sin embargo, recientemente se ha determinado que solo el 14 por ciento de las especies de anfibios han exhibido quitridiomicosis (Heard, 2011). Esto indicaría que la reducción de la población de anfibios y las extinciones mundiales de especies tienen causas multifactoriales, incluido el componente epizoótico y su interacción con los componentes ambientales (i. e., la vulnerabilidad de Bd a los rangos de temperatura y humedad), pero puede no ser la etiología principal.

Agradecimientos. Al apoyo del Programa de Becas Posdoctorales de la Dirección General de Asuntos de Personal Académico de la Universidad Nacional Autónoma de México (UNAM) otorgado a LMGF. Este proyecto fue posible gracias a la contribución financiera de PAPIIT No. N210410-3 para DMB. El muestreo de A. mexicanum fue facilitado por el Centro de Investigaciones Biológicas y Acuícolas de Cuemanco de la Universidad Autónoma Metropolitana. Fahd Henry Carmona Torres (DEFSAL-FMVZ) proporcionó algunas muestras de poblaciones silvestres. Shiara González-Padrón y Sein Cervantes por su apoyo en el trabajo de campo. A Carolina Segundo-Zaragoza por facilitar las actividades en el Laboratorio de Micología, FMVZ-UNAM. La identificación de especies de anfibios se realizó con la ayuda de René Murrieta-Galindo.

\section{LITERATURA CITADA}

Andre, S. E., Parker, J., Briggs, C. J. (2008) Effect of temperature on host response to Batrachochytrium dendrobatidis infection in the mountain yellow-legged frog (Rana muscosa). Journal of Wildlife Diseases, 44, 716-720. https://doi.org/10.7589/0090-3558-44.3.716 
Beard, K. H., O'Neill, E. M. (2005) Infection of an invasive frog Eleutherodactylus coqui by the chytrid fungus Batrachochytrium dendrobatidis in Hawaii. Biological Conservation, 126, 591-595. https://doi.org/10.1016/j.biocon.2005.07.004

Bell, J. F. (1996) Application of classification trees to the habitat preference of upland birds. Journal of Applied Statistic, 23, 349-359. https://doi.org/10.1080/02664769624297

Berger, L., Speare, R., Daszak, P., Green, D. E., Cunningham, A. A., Goggin, C. L., Slocombe, R., Ragan, M. A., Hyatt, A. D., McDonald, K. R., Hines, H. B., Lips, K. R., Marantelli, G., Parkes, H. (1998) Chytridiomycosis causes amphibian mortality associated with population declines in the rain forests of Australia and Central America. Proceedings of National Academy of Science, 95, 9301-9306. https://doi.org/10.1073/pnas.95.15.9031

Berger, L., Speare, R., Hines, H. B., Marantelli, G., Hyatt, A. D., McDonald, K. R., Skerratt, L. F., Olsen, V., Clarke, J. M., Gillespie, G., Mahony, M., Sheppard, N., Williams, C., Tyler, M. J. (2004) Effect of season and temperature on mortality in amphibians due to chytridiomycosis. Australian Veterinary Journal, 82, 31-36. https://doi.org/10.1111/j.1751-0813.2004.tb11137.x

Briggs, C. J., Knapp, R. A., Vredenburg, V. T. (2010) Enzootic and epizootic dynamics of the chytrid fungal pathogen of amphibians. Proceedings of the National Academy of Science, 107, 9695-9700. https://doi.org/10.1073/pnas.0912886107

Bosch, J., Martínez-Solano, I., García-París, M. (2001) Evidence of a chytrid fungus infection involved in the decline of the common midwife toad (Alytes obstetricans) in protected areas of central Spain. Biology Conservation, 97, 331-337. https://doi.org/10.1016/S0006-3207(00)00132-4

Bradley, G. A., Rosen, P. C., Sredl, M. J., Jones, T. R., Longcore, J. E. (2002) Chytridiomycosis in native Arizona frogs. Journal of Wildlife Diseases, 38, 206-212. https://doi.org/10.7589/0090-3558-38.1.206

Breiman, L., Friedman, J., Stone, C. J., Olshen, R. A. (1984) Classification and regression trees. CRC press. New York, USA.

Burgin, S., Schell, C. B., Briggs, C. (2005) Is Batrachochytrium dendrobatidis really the proximate cause of frog decline? Acta Zoologica Sinica, 51, 344-348.

Bustamante, H., Livo, L. J., Carey, C. (2012) Effects of temperature and hydric environment on survival of the Panamanian Golden Frog infected with a pathogenic chytrid fungus. Integrative Zoology, 5, $143-153$. https://doi.org/10.1111/j.1749-4877.2010.00197.x

Carnaval, A. C., Puschendorf, R., Peixoto, O. L., Verdade, V. K., Rodrigues, M. T. (2006) Amphibian chytrid fungus broadly distributed in the Brazilian Atlantic rain forest. EcoHealth, 3, 41-48. https://doi.org/10.1007/s10393-005-0008-2

Cashins, S. D. (2009) Epidemiology of chytridiomycosis in rainforest stream tadpoles. PhD Dissertation. James Cook University. Australia, 207 pp.

CONAGUA (2011) Comisión Nacional del Agua. Servicio Meteorológico Nacional. Disponible en: http://smn.cna.gob.mx/climatologia/analisis/reporte/Anual2011.pdf (Acceso en julio de 2017).

Daskin, J. H., Bell, S. C., Schwarzkopf, L., Alford, R. A. (2014) Cool temperatures reduce antifungal activity of symbiotic bacteria of threatened amphibians-implications for disease management and patterns of decline. PLoS ONE, 9, e100378. https://doi.org/10.1371/journal.pone.0100378

Daszak, P., Cunningham, A. A., Hyatt, A. D. (2003) Infectious diseases and amphibian population declines. Diversity and Distribution, 9, 141-150. https://doi.org/10.1046/j.1472-4642.2003.00016.x 
García-Feria et al.: Determinantes para la presencia de Batrachochytrium

dendrobatidis en anfibios

Flechas, S. V., Sarmiento, C., Amézquita, A. (2012) Bd on the Beach: High Prevalence of Batrachochytrium dendrobatidis in the Lowland Forests of Gorgona Island (Colombia, South America). EcoHealth, 9, 298-302. https://doi.org/10.1007/s10393-012-0771-9

Frías-Álvarez, P. P., Vrendenburg, V. T., Familiar-López, M., Longcore, J. E., González-Bernal, E., Santos-Barrera, G., Zambrano, L., Parra-Olea, G. (2008) Chytridiomycosis survey in wild and captive Mexican amphibians. EcoHealth, 5, 18-26. https://doi.org/10.1007/s10393-008-0155-3

Gaertner, J. P., Forstner, M. R. J., O'Donnell, L., Hall, D. (2009) Detection of Batrachochytrium dendrobatidis in endemic salamander species from Central Texas. EcoHealth, 6, 20-26. https://doi.org/10.1007/s10393-009-0229-x

Goka, K., Yokoyama, J., Une, Y., Kuroki, T., Suzuki, K., Nakahara, M., Kobayashi, A., Inaba, S., Mizutani, T., Hyatt, A. D. (2009) Amphibian chytridiomycosis in Japan: distribution, haplotypes and possible route of entry into Japan. Molecular Ecology, 18, 4757-4774. https://doi.org/10.1111/j.1365-294X.2009.04384.x

Gosner, K. L. (1960) A simplified table for staging anuran embryos and larvae with notes on identification. Herpetologica, 16, 183-190. www.jstor.org/stable/3890061.

Gotelli, N. J., Ellison, A. M. (2004) A primer of ecological statistics. Sinauer Associates. Sunderland, MA, EUA.

Gray, M. J., Duffus, A. L. J., Haman, K. H., Harris, R. N., Allender, M. C., Thompson, T. A., Christman, M. R., Zacerdote-Velat, A., Sprague, L. A., Williams, J. M., Miller, D. L. (2017) Pathogen surveillance in herpetofaunal populations: guidance on study design, sample collection, biosecurity and intervention strategies. Herpetological Review, 48 (2), 334-351.

Gründler, M. C., Toledo, L. F., Parra-Olea, G., Haddad, C. F. B., Giasson, L. O. M., Sawaya, R. J., Prado, C. P. A., Araujo, O. G. S., Zara, F. J., Centeno, F. C., Zamudio, K. R. (2012) Interaction between breeding habitat and elevation affects prevalence but not infection intensity of Batrachochytrium dendrobatidis in Brazilian anuran assemblages. Diseases and Aquatic Organisms, 97, 173-184. https://doi.org/10.3354/dao02413

Heard, M., Smith, K. F., Ripp, K. (2011) Examining the evidence for Chytridiomycosis in threatened amphibian species. PLos ONE, 6, e23150. https://doi:10.1371/journal.pone.0023150

Hernández-López, P., Santiago-Alarcón, D., López-Velázquez, A. (2018) Factores ecológicos que afectan la infección por Batrachochytrium dendrobatidis en anfibios de México. pp. 53-78, en: López-Velázquez, A., Basanta, M. D., Ochoa-Ochoa, L. M. (Eds.). Quitridiomicosis en México. Publicaciones de la Sociedad Herpetológica Mexicana No. 5.

Heumann, C., Schomaker, M., Shalabh. (2016) Introduction to statistic and data analysis: with exercises, solutions and applications in R. Springer.

INEGI (2017) Anuario Estadístico y Geográfico de Tabasco-2017. Instituto Nacional de Estadística, Geografía e Informática, Gobierno del Estado de Tabasco. 440 pp.

IUCN (2017) International Union for Conservation of Nature. IUCN red list of threatened species. Version 2017.3. Disponible en: http://www.iucnredlist.org (acceso en mayo de 2018).

James, T. Y., Litvintseva, A., Vilgalys, R., Morgan, J. A. T., Taylor, J. W., Fisher, M. C., Berger, L., Weldon, C., du Preez, L., Longcore, J. E. (2009) Rapid expansion of an emerging fungal disease into declining and healthy amphibian populations. PLoS Pathogens, 5, e1000458. http://doi:10.1371/journal.ppat.1000458

Johnson, M. L., Speare, R. (2005) Possible modes of dissemination of the amphibian chytrid Batrachochytrium dendrobatidis in the environment. Diseases of Aquatic Organism, 65, 181-186. https://doi:10.3354/dao065181 
Kawada, J., Kimura, H., Ito, Y., Hoshino, Y., Tanaka-Kitajima, N., Ando, Y., Futamura, M., Morishina, T. (2004) Comparison of real-time and nested PCR assay for detection of herpes simplex virus DNA. Microbiology Immunology, 48, 411-415. https://doi.org/10.1111/j.1348-0421.2004.tb03530.x

Kilpatrick, A. M., Briggs, C. J., Daszak, P. (2010) The ecology and impact of chytridiomycosis: an emerging disease of amphibians. Trends in Ecology and Evolution, 25, 109-18. https://doi.org/10.1016/j.tree.2009.07.011

Kriger, K. M., Hero, J. M., Ashton, K. J. (2006) Cost efficiency in the detection of chytridiomycosis using PCR assay. Diseases of Aquatic Organism, 71, 149-154. https://doi.org/10.3354/dao071149

Kriger, K. M., Hero, J. M. (2007) The chytrid fungus Batrachochytrium dendrobatidis is non-randomly across amphibian breeding habitats. Diversity and Distributions, 13, 781-788. https://doi.org/10.1111/j.1472-4642.2007.00394.x

Kriger, K. M., Hero J. M. (2008) Altitudinal distribution of chytrid (Batrachochytrium dendrobatidis) infection in subtropical Australian frogs. Austral Ecology, 33, 1022-1032. https://doi.org/10.1111/j.1442-9993.2008.01872.x

Laurence, W. F. (1996) Epidemic disease and the catastrophic decline of Australian rain forest frogs. Conservation Biology, 10, 406-413. https://www.jstor.org/stable/2386857

Laurence, W. F., McDonald, K. R., Speare, R. (1997) In defense of the epidemic disease hypothesis. Conservation Biology, 11, 1030-1034. https://www.jstor.org/stable/2387341

Lips, K. R., Reeve, J. D., Witters, L. R. (2003) Ecological traits predicting amphibian population declines in Central America. Conservation Biology, 17, 1078-1088. https://doi.org/10.1046/j.1523-1739.2003.01623.x

Lips, K. R., Mendelson III, J. R., Muñoz-Alonso, A., Canseco-Márquez, L., Malcahy, D. G. (2004) Amphibian population declines in montane southern Mexico: resurveys of historical localities. Biological Conservation, 119, 555-564. https://doi.org/10.1016/j.biocon.2004.01.017

Longcore, J. E., Pessier, A. P., Nichols, D. K. (1999) Batrachochytrium dendrobatidis gen. Et sp. Nov., a chytrid pathogenic to amphibians. Mycologia, 91, 219-227. https://www.jstor.org/stable/3761366

Longmire, J. L., Maltbie, M., Baker, R. J. (1997) Use of "lysis buffer" in RNA isolation and its implications for museum collections. Occasional Papers, Museum of Texas Tech University, 163, $1-3$.

Longo, A. V., Burrowes, P. A. (2010) Persistence with chytridiomycosis does not assure survival of directdeveloping frogs. EcoHealth, 7, 185-195. https://doi.org/10.1007/s10393-010-0327-9

López-Velázquez, A. (2018) Ocurrencia de la quitridiomicosis en México. pp. 35-52, en: López-Velázquez A., Basanta, M. D., Ochoa-Ochoa, L. M. (Eds). Quitridiomicosis en México. Publicación especial de la Sociedad Herpetológica Mexicana A. C. No. 5.

Luja, V. H., Rodríguez-Estrella, R., Ratzlaff, K., Parra-Olea, G., Ramírez-Bautista, A. (2012) The chytrid fungus Batrachochytrium dendrobatidis in isolated populations of the Baja California treefrog Pseudacris hypochondriaca curta in Baja California Sur, Mexico. The Southwestern Naturalist, 57, 323-355. https://doi.org/10.1894/0038-4909-57.3.323

Ma, Z., Luo, Y., Michailides, T. J. (2003) Nested PCR assay for detection of Monilinia fructicola in stone fruit Orchards and Botryosphaeria dithidea from pistachios in California. Journal of Phytopathology, 151, 312-322.

https://doi.org/10.1046/j.1439-0434.2003.00725.x 
García-Feria et al.: Determinantes para la presencia de Batrachochytrium

dendrobatidis en anfibios

Marantelli, G., Berger, L., Speare, R., Keegan, L. (2004) Distribution of the amphibian chytrid Batrachochytrium dendrobatidis and keratin during tadpole development. Pacific Conservation Biology, 10 (3), 173-179.

McCallum, H. (2005) Inconclusiveness of Chytridiomycosis as the agent in widespread frog declines. Conservation Biology, 19, 1421-1430. https://doi.org/10.1111/j.1523-1739.2005.00217.x

McCracken, S., Gaertner, J. P., Forstner, M. R. J., Hahn, D. (2009) Detection of Batrachochytrium dendrobatidis in amphibians from the forest floor to the upper canopy of an Ecuadorian Amazon lowland rainforest. Herpetological Review, 40, 190-195.

Mendoza-Almeralla, C., Burrowes, P., Parra-Olea, G. (2015) La quitridiomicosis en los anfibios de México: una revisión. Revista Mexicana de Biodiversidad, 86, 238-248. https://doi.org/10.7550/rmb.42588

Miller, S. A., Dykes, D. D., Polesky, H. F. (1988) A simple salting out procedure for extracting RNA from human nucleated cells. Nucleic Acids Research, 16, 1215.

Muñoz-Alonso, L. A. (2013) Riqueza, diversidad y estatus de los anfibios amenazados en el sureste de México; una evaluación para determinar las posibles causas de la declinación de sus poblaciones. El Colegio de la Frontera Sur-Critical Ecosystem Parthernship Fund-Arizona State University. Disponible en: http://www.cepf.net/Documents/final_Ecosur_amphibians_mexico.pdf

Murrieta-Galindo, R., Parra-Olea, G., González-Romero, A., López-Barrerā, F., Vredenburg, V. T. (2014) Detection of Batrachochytrium dendrobatidis in amphibians inhabiting cloud forests and coffee agroecosystems in central Veracruz, Mexico. European Journal of Wildlife Research, 60, 431-439.

https://doi.org/10.1007/s10344-014-0800-9

Nichols, D. K., Lamirande, E. W., Pessier, A. P., Longcore, J. E. (2001) Experimental transmission of cutaneous chytridiomycosis in dendrobatid frogs. Journal of Wildlife Diseases, 37, 1-11. https://doi.org/10.7589/0090-3558-37.1.1

O'Hanlon, S. J., Rieux, A., Farrer, R. A., Rosa, G. M., Waldam, B., Bataille, A., Kosch, T. A., Murray, K. A., Brankovics, B., Fumagalli, M., Martin, M. D., Wales, N., Alvarado-Rybak, M., Bates, K. A., Berger, L., Böll, S., Brookes, L., Clare, F., Courtois, E. A., Cunningham, A. A., DohertyBone, T. M., Ghosh, P., Gower, D. J., Hintz, W. E., Höglund, J., Jenkinson, T. S., Lin, C-F., Laurila, A., Loyau, A., Martel, A., Meurling, S., Miaud, C., Minting, P., Pasmans, F., Schmeller, D. S., Schmidt, B. R., Shelton J. M .G., Skerrat, L. F., Smith, F., Soto-Azat, C., Spagnoletti, M., Tessa, G., Toledo, L. F., Valenzuela-Sánchez, A., Verster, R., Vörös, J., Webb, R. J., Wierzbicki, C., Wombwell, E., Zamudio, K. R., Aanensen, D. M., James, T. Y., Gilbert, M. T. P., Weldon, C., Bosch, J., Balloux, F., Garner, T. W. J., Fisher, M. C. (2018) Recent Asian origin of chytrid fungi causing global amphibian declines. Science, 360, 621-627.

Piotrowski, J. S., Annis, S. L., Longcore, J. E. (2004) Physiology of Batrachochytrium dendrobatidis, a chytrid pathogen of amphibians. Mycologia, 96, 9-15.

https://doi.org/10.1080/15572536.2005.11832990

Piova-Scott, J., Pope, K. L., Lawer, S. P., Cole, E. M., Foley, J. E. (2011) Factors related to the distribution and prevalence of the fungal pathogen Batrachochytrium dendrobatidis in Rana cascadae and other amphibians in the Klamath Mountains. Biological Conservation, 144, 2913-2921.

https://doi.org/10.1016/j.biocon.2011.08.008

Pounds, A. J., Bustamonte, M. R., Coloma, L. A., Consuegra, J. A., Fogden, M. P. L., Foster, P. N., La Marca, E., Masters, K. L., Merino-Viteri, A., Puschendorf, R., Ron, S. R., Sanchez-Azofeifa, G. A., Still, C. J., Young, B. E. (2006) Widespread amphibian extinctions from epidemic disease driven by global warming. Nature, 439, 161-167.

https://doi.org/10.1038/nature04246

Puschendorf, R., Bolaños, F., Chaves, G. (2006) The amphibian chytrid fungus along an altitudinal transect before the first reported declines in Costa Rica. Biological Conservation, 132, 136-142. https://doi.org/10.1016/j.biocon.2006.03.010 
Quintero-Díaz, G. E. (2004) Frecuencia de anormalidades y evidencias de infección por un hongo quítrido en larvas de anuros en dos zonas montañosas de Chiapas. Tesis de Maestría. El Colegio de la Frontera Sur, ECOSUR.

Rachowicz, L. J. (2002) Mouthpart pigmentation in Rana muscosa tadpoles: seasonal changes without chytridiomycosis. Herpetology Review, 33, 263-265.

Rachowicz, L. J., Hero, J. M., Alford, R. A., Taylor, J. W., Morgan, J. A. T., Vredenburg, V. T., Collins, J. P., Briggs, C. J. (2005) The novel and endemic pathogen hypotheses: competing explanations for the origin of emerging infectious diseases of wildlife. Conservation Biology, 19, 1441-1448. https://doi.org/10.1111/j.1523-1739.2005.00255.x

Rohr, J. R., Raffel, T. R. (2010) Linking global climate and temperature variability to widespread amphibian declines putatively caused by disease. Proceedings of Natural Academy of Science, 107, $8269-8274$. https://doi.org/10.1073/pnas.0912883107

Rollins-Smith, L. A., Reinert, L. K., Miera, V., Conlon, J. M. (2002) Antimicrobial peptide defenses of the Tarahumara frog, Rana tarahumarae. Biochemical and Biophysical Research Communications, 297, 361-367. https://doi.org/10.1016/S0006-291X(02)02217-9

Searle, C. L., Biga, L. M., Spatafora, J. W., Blaustein, A. R. (2011) A dilution effect in the emerging amphibian pathogen Batrachochytrium dendrobatidis. Proceedings of the National Academy of Science, 108, 16322-16326. https://doi.org/10.1073/pnas.1108490108

Sinclair, A.R.E., Fryxell, J. M., Caughley, G. (2006) Wildlife ecology, conservation, and management. Second edition. Blackwell Publishing Ltd.

Skerrat, L. F., Berger, L., Hines, H. B., McDonald, K. R., Mendez, D., Speare, R. (2008) Survey protocol for detecting chytridiomycosis in all Australian frog populations. Diseases of Aquatic Organism, $80,85-94$. https://doi.org/10.3354/dao01923

Slenning, B. D. (2010) Global climate change and implications for disease emergence. Veterinary Pathology, 47, 28-33. https://doi.org/10.1177/0300985809354465

Smith, K. G., Weldon, C., Conradie, W., du Preez, L. H. (2007) Relationships among size, development, and Batrachochytrium dendrobatidis infection in African tadpoles. Diseases of Aquatic Organisms, 74, 159-164. https://doi.org/10.3354/dao074159

Sodhi, N. S., Bickford, D., Diesmos, A. C., Lee, T. M., Koh, L. P., Brooks, B. W., Sekercioglu, C. H., Bradshaw, C. J. A. (2008) Measuring the meltdown: drivers of global amphibian extinction and decline. PLoS ONE, 3, e1636. https://doi.org/10.1371/journal.pone.0001636

Stuart, S. N., Chanson, J. S., Cox, N. A., Young, B. E., Rodrigues, A. S. L., Fischman, D. L., Waller, R. W. (2004) Status and trends of amphibian declines and extinctions worldwide. Science, 306, 17831786. https://doi.org/10.1126/science. 1103538

Toledo, L. F., Britto, F. B., Araujo, O. G. S., Giasson, L. M. O., Haddad, C. F. B. (2006) The occurrence of Batrachochytrium dendrobatidis in Brazil and the inclusion of 17 new cases of infection. South American Journal of Herpetology, 1, 185-191. https://doi.org/10.2994/1808-9798(2006)1[185:TOOBDI]2.0.CO;2

Vayssières, M. P., Plant, R. E., Allen-Diaz, B. H. (2000) Classification trees: An alternative non-parametric approach for predicting species distributions. Journal of Vegetation Science, 11, 679-694. https://doi.org/10.2307/3236575 
García-Feria et al.: Determinantes para la presencia de Batrachochytrium

dendrobatidis en anfibios

Voyles, J., Young, S., Berger, L., Campbell, C., Voyles, W. F., Dinudom, A., Cook, D., Webb, R., Alford, R. A., Skerratt, L. F., Speare, R. (2009) Pathogenesis of chytridiomycosis, a cause of catastrophic amphibian declines. Science, 326, 582-585. https://doi.org/10.1126/science.1176765

Weldon, C., du Preez, L. H., Hyatt, A. D., Muller, R., Speare, R. (2004) Origin of the amphibian chytrid fungus. Emerging Infectious Diseases, 10, 2100-2105. https://dx.doi.org/10.3201/eid1012.030804

Whitfield, S. M., Kerby, J., Gentry, L. R., Donnelly, M. A. (2012) Temporal variation in infection prevalence by the amphibian chytrid fungus in the species of frogs at La Selva, Costa Rica. Biotropica, 44, 779-784. https://doi.org/10.1111/j.1744-7429.2012.00872.x

Woodhams, D. C., Alford, R. A. (2005) Ecology of chytridiomycosis in rainforest stream frog assemblages of tropical Queensland. Conservation Biology, 19, 1449-1459. https://doi.org/10.1111/j.1523-1739.2005.004403.x

Woodhams, D. C., Alford, R. A., Briggs, C. J., Johnson, M., Rollins-Smith, L. A. (2008) Life-history trade-offs influence disease in changing climates: Strategies of an amphibian pathogen. Ecology, $89,1627-1639$.

https://doi.org/10.1890/06-1842.1 